Commonplace • Series 1.3: Global Transition to Open

\title{
The Open Transition Takes \\ Center Stage
}

Sharla Lair, Curtis Brundy

Published on: Nov 16, 2021

DOI: $10.21428 / 6 \mathrm{ffd} 8432.3 \mathrm{e} 4 \mathrm{dfdae}$

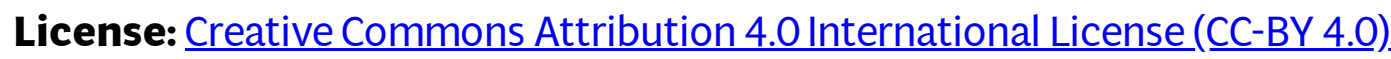


Since the release of the call for contributions for the Global Transition to Open: Structuring Library Sustainability Toward a More Equitable Knowledge Ecosystem

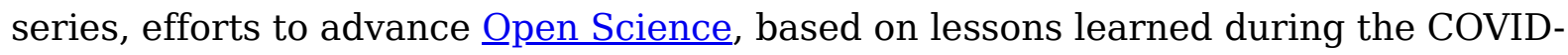
19 pandemic, have accelerated, including in the area of open access. Most recently, a joint Creative Commons, EIFL, and SPARC initiative, funded by the Open Society Foundations, launched to identify the important climate and biodiversity articles locked behind publisher paywalls. Like paywalled COVID-19 related articles publishers made freely available in the face of a global health crisis, this new initiative will highlight and help open up the critical publications needed to address the climate crisis that are also inexplicably and unfortunately locked away.

The urgency to accelerate science, to accelerate knowledge creation, is, of course, not restricted to the COVID-19 pandemic and climate change crises. It is felt across all areas of research, from those that directly impact human health to those that impact the environment, economy, education, and beyond. Cable Green, who will lead the new Creative Commons, EIFL, and SPARC initiative to unlock the climate literature, accurately points out that "During the COVID-19 crisis, the power of open access to democratize knowledge sharing, accelerate discovery, promote research collaboration, and bring together the efforts of global stakeholders to tackle the pandemic took center stage." Our challenge ahead will be to ensure that the position of open access at center stage during the pandemic is a springboard to place it center stage across the many other areas of inquiry that stand to benefit ourselves, our friends, our families, and our world.

The goal of the Global Transition to Open series is to show the ways libraries, library consortia, and publishers are responding to this moment of urgency and transition when change in scholarly publishing and open access is not only possible but is actively taking place. The contributions we received did not disappoint. Together they present a portrait of transformation that is instructive and inspiring.

We would like to dedicate space in this letter to express our gratitude to the 24 authors representing Africa, Australia, Europe, North America, and South America who used their time and energy to contribute 15 responses to this conversation. We would also like to thank Annie Johnson, who inspired this conversation through her Commonplace contribution titled "Balancing Investments in Open Access: Sustainability and Innovation." Finally, we would like to thank Catherine Ahearn, Sarah Kearns, and Allison Vanouse from Commonplace for helping us realize this blog series. 
We do not take for granted the privilege that Knowledge Futures Group extends to global communities that congregate around knowledge. They are realizing their vision of equitable and inclusive discourse by way of the PubPub platform and the amazing staff that maintains the infrastructure and communities that rely upon it.

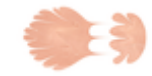

The content and structure of this blog series are influenced by the open nature of our call for proposals. Because the topics covered are varied, we did make an effort to impose structure based on themes that emerged. As we went through this sensemaking exercise, we identified three themes: Values and Principles; Communities and Collaboration, and; Ideation, Strategy, and Operationalization. Many of the articles touch on each of these themes, however, we sorted them based on the dominant lens through which the authors were looking as they told their story, admittedly with an interest in emphasizing the array of entry points that libraries can take when transforming how they steward funds.

The contributions under the Values and Principles theme reveal a massive rethinking about the roles that scholars, libraries, consortia, and publishers can take to recalibrate the scholarly publishing landscape so that it is more aligned with shared values such as diversity, equity, inclusion, and accessibility, as well as, sustainability, transparency, and openness.

Values and Principles are not designed to be passive. Rather they must be acted out. It is a lot easier to act them out when structures do not prohibit you from doing so. The series contributions under the Ideation, Strategy, and Operationalization theme acknowledge the flaws in our current systems that are prohibiting us from acting out our values and provide innovative solutions so that we might advance a different reality.

Evermore libraries around the world are now plunged into austerity and as a result, there is an emerging conversation about how we can collectively move the needle toward openness. The Communities and Collaboration themed contributions in this series talk of re-imagining our communities and the connection infrastructure that supports collaboration. Internalizing values of care and looking after each other levels the playing field so that multiple stakeholders can equitably participate in our shared scholarly communication community.

We hope you enjoy reading the articles in this series as much as we did. And we would encourage you to take advantage of PubPub's commenting feature to let the authors 
know your thoughts and questions. What did you find inspiring? What did you find that you may put to use in your own organization? And, of course, where might you disagree?

Commonplace has emerged at an opportune time, providing an important home for sharing the ideas and voices behind the transition to an open and equitable scholarly publishing landscape. If you have thoughts on the overall series-including ideas for future series themes-we would love to hear them, so please get in touch. 